\section{Occurrence of bisphenol A in wastewater and wastewater sludge of CUQ treatment plant}

\author{
Dipti Prakash Mohapatra, ${ }^{1}$ \\ Satinder Kaur Brar, ${ }^{1}$ \\ Rajeshwar Dayal Tyagi, ${ }^{1}$ \\ Rao Y. Surampalli² \\ 'INRS-ETE, Université du Québec, \\ Québec, Canada; ${ }^{2}$ US Environmental \\ Protection Agency, Kansas City, USA
}

\section{Abstract}

The identification and quantification of bisphenol A (BPA) in wastewater (WW) and wastewater sludge (WWS) is of major interest to assess the endocrine activity of treated effluent discharged into the environment. BPA is manufactured in high quantities fro its use in adhesives, powder paints, thermal paper and paper coatings among others. Due to the daily use of these products, high concentration of BPA was observed in WW and WWS. BPA was measured in samples from Urban Community of Quebec wastewater treatment plant located in Quebec (Canada) using LC-MS/MS method. The results showed that BPA was present in significant quantities $\left(0.07 \mu \mathrm{g} \mathrm{\textrm {L } ^ { - 1 }}\right.$ to $1.68 \mu \mathrm{g} \mathrm{\textrm {L } ^ { - 1 }}$ in wastewater and $0.104 \mu \mathrm{g} \mathrm{g}^{-1}$ to $0.312 \mu \mathrm{g} \mathrm{g}^{-1}$ in wastewater sludge) in the wastewater treatment plant (WWTP). The treatment plant is efficient (76\%) in removal of pollutant from process stream, however, environmentally significant concentrations of $0.41 \mu \mathrm{g} \mathrm{L} \mathrm{L}^{-1}$ were still present in the treated effluent. Rheological study established the partitioning of BPA within the treatment plant. This serves as the base to judge the portion of the process stream requiring more treatment for degradation of BPA and also in selection of different treatment methods. Higher BPA concentration was observed in primary and secondary sludge solids (0.36 and $0.24 \mu \mathrm{g} \mathrm{g}^{-1}$, respectively) as compared to their liquid counterpart ( 0.27 and $0.15 \mu \mathrm{g} \mathrm{L} \mathrm{L}^{-1}$, respectively) separated by centrifugation. Thus, BPA was present in significant concentrations in the WWTP and mostly partitioned in the solid fraction of sludge (Partition coefficient $\left(\mathrm{K}_{d}\right)$ for primary, secondary and mixed sludge was $0.013,0.015$ and 0.012 , respectively).

\section{Introduction}

The distribution and abundance of plastic particles in the environment has rapidly increased, and the adverse effects of organic compounds that leach from the plastic debris on aquatic animals have been lately of great concern. Some of these compounds also referred to as endocrine disrupting compounds (EDCs) have the potential to cause serious effects on wildlife and human health, at very low concentrations. Bisphenol A (BPA) has been identified as EDC by U.S Environmental Protection Agency (EPA), World Wide Fund for Nature (WWF). ${ }^{1,2}$

$\mathrm{BPA}$ is released into the environment either through sewage treatment effluent, ${ }^{3}$ landfill leachate (via hydrolysis of BPA from plastics ${ }^{4}$ ), or natural degradation of polycarbonate plastics. Sewage effluent and landfill leachate are point sources of BPA in the environment, fragments of epoxy resins and polycarbonate plastic debris entering the watershed through runoff are non-point sources. Industrial releases of BPA to the environment are likely to come from wastewaters and washing residue produced during production and processing of products, fugitive dust freed during handling and minor volatilization losses during manufacturing. ${ }^{5}$ BPA may enter the environment through possible physical and chemical breakdown during disposal and recycling operations within wastewater treatment plants (WWTPs) and also by release from manufacturing industries. Table $1^{2,6}$ presents physico-chemical characteristics of BPA and its uses in different manufacturing industries. This suggests the important use of this chemical in various industrial activity.

One of the main sources of BPA is untreated urban wastewater and WWTP effluents. ${ }^{3}$ Most current WWTPs are not designed to treat emerging contaminants including BPA. As a result high portion of emerging contaminants including BPA and their metabolities can escape elimination in WWTPs and enter the aquatic environment via sewage effluents. Various studies have been already carried out to remove BPA in wastewater. ${ }^{2}$

The behavior and removal of BPA within WWTP depends on its physicochemical properties and on WWTP configuration and operation. Major removal pathways of BPA in sludge include: i) adsorption to the sludge, ii) biological degradation and transformation. ${ }^{6,7}$ Recently, considerable interest has been shown in the identification, trace concentration analysis and degradation of BPA in aqueous environment due to advances in analytical techniques. $^{8-10}$

BPA concentrations present in sewage sludge could be released to soil through the application of sludge biosolids to agricultural lands. ${ }^{5}$ The draft assessment report submitted by Canada Gazette to Health Canada concluded that BPA can cause harmful effects to aquatic organisms with chronic exposure at levels below those usually seen with brief low-dose exposure, particularly at sensitive develop-
Correspondence: SK Brar, INRS-ETE, Université du Québec, 490, Rue de la Couronne, Québec, Canada G1K 9A9.

Tel. +1.418.654 3116 - Fax: +1.418.6542600.

E-mail: satinder.brar@ete.inrs.ca

Key words: bisphenol A, partitioning, rheology, wastewater, wastewater sludge.

Acknowledgements: the authors are sincerely thankful to the Natural Sciences and Engineering Research Council of Canada (Discovery Grants 355254, Canada Research Chair) and INRS-ETE for financial support. The views or opinions expressed in this article are those of the authors and should not be construed as opinions of the U.S. Environmental Protection Agency.

Received for publication: 29 June 2011. Accepted for publication: 23 August 2011.

This work is licensed under a Creative Commons Attribution NonCommercial 3.0 License (CC BYNC 3.0).

(OCopyright D.P. Mohapatra et al., 2011

Licensee PAGEPress, Italy

Journal of Xenobiotics 2011; 1:e3

doi:10.4081/xeno.2011.e3

mental stages to subsequent generations and by using more than one mode of action. ${ }^{11}$

Thus, the identification and quantification of BPA in wastewater (WW) and wastewater sludge (WWS) is of major interest to assess the endocrine activity of WWTPs discharged into the environment and to identify the processes that are more effective in reducing the environmental impacts associated with the pollutant.

Moreover, most of the studies so far have confirmed the presence of BPA in WW and WWS $^{12-15}$ and performed mass balance by only concentrating on the total samples, neglecting the partitioning in solid and liquid fraction which is an important entity for fate of BPA within WWTPs. Additionally, all studies have so far related the presence of BPA to physicalchemical-biological processing and not taking into account the rheology of the fluid streams in WWTPs. Rheology, comprising apparent viscosity and particle size affect the removal of BPA from WWS as decrease in viscosity and particle size during different treatment steps of WWTPs enhance BPA adsorption and desorption and thus degradation. The decreased particle size can also improve access of by microbial enzymes to BPA favoring biodegradation of pollutant in biological treatment steps. In fact, lower particle size and viscosity have been known to enhance the biodegradation of wastewater sludge. ${ }^{16}$ Thus, in present study, the presence of BPA in the process streams and residues of a WWTP in Quebec, Canada was investigated. The study involved: i) quantification of BPA in raw samples of influent, grit 
influent, effluent, primary, secondary, mixed and dewatered sludge; ii) quantification of BPA in solid and liquid fraction of each sludge to estimate partitioning of BPA into two compartments; iii) estimation of the amount of BPA released in the treated effluent and process residues; and d) effect of rheology of WW samples on BPA removal/degradation in WWTP.

\section{Experimental}

\section{Chemicals and standards}

BPA (98\% purity assay) was obtained from Sigma-Aldrich (Ontario, Canada). HPLC-grade methanol $(\mathrm{MeOH})$, dichloromethane (DCM), acetone and chloroform, used for cleaning and extraction purposes, were purchased from Fisher Scientific (Ontario, Canada). OASIS HLB 5 cc $200 \mathrm{mg}$ LP glass cartridges used for solid phase extraction (SPE) clean-up was purchased from Waters (Milford, MA, USA). Acetic acid and sulfuric acid were supplied by Fisher scientific (Ontario, Canada). HPLC grade water was prepared in the laboratory using a Milli-Q/Milli-RO Millipore system (Milford, MA, USA).

\section{Description of WWTP}

Samples were collected from Quebec Urban Community (CUQ) wastewater treatment plant (Beauport, Quebec city, Quebec, Canada) which

Table 1. Physico-chemical characteristics and uses of bisphenol $\mathrm{A}$.

Structure

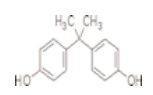

Molecular formula $\mathrm{C}_{15} \mathrm{H}_{16} \mathrm{O}_{2}$

\begin{tabular}{ll} 
Molar mass & $228.29 \mathrm{~g} \mathrm{~mol}^{-1}$ \\
Density & $1.20 \mathrm{~g} \mathrm{~cm}^{-3}$ \\
\hline
\end{tabular}

Water solubility $\quad<100 \mathrm{mg} \mathrm{L}^{-1}\left(21.5^{\circ} \mathrm{C}\right)$

$120 \mathrm{mg} \mathrm{L}-1\left(20-25^{\circ} \mathrm{C}\right)$

$300 \mathrm{mg} \mathrm{L}-1\left(20-25^{\circ} \mathrm{C}\right)$

120-200 mg L-1 $\left(20-25^{\circ} \mathrm{C}\right)$

\begin{tabular}{ll} 
Melting point & $158-159^{\circ} \mathrm{C}$ \\
& $157^{\circ} \mathrm{C}$ \\
& $153^{\circ} \mathrm{C}$ \\
\hline Boiling point & $220^{\circ} \mathrm{C}(4 \mathrm{~mm} \mathrm{Hg})$ \\
& $398^{\circ} \mathrm{C}(760 \mathrm{~mm} \mathrm{Hg})$ \\
Vapor pressure & $87 \mathrm{~Pa}\left(190^{\circ} \mathrm{C}\right)$ \\
\hline Log $\mathrm{K}_{\text {ow }}$ & $2.30-3.82$ \\
Appearance & White crystalline solid \\
\hline Uses & Production of adhesives, \\
& protective coatings, \\
& powder paints, automotive \\
& lenses, thermal paper, paper \\
& $\begin{array}{l}\text { coatings, protective window } \\
\text { glazing, building materials, }\end{array}$ \\
& compact disks, as a \\
& developer in dyes, optical \\
& lenses and for encapsulation \\
& of electrical and electronic \\
& parts
\end{tabular}

receives wastewater originating from domestic zones, industries, commercial enterprises and institutions present in the city. The eastern station of WWTP serves a population of 528,016 (2006 estimate) and has a treatment capacity of $400,000 \mathrm{~m}^{3}$ day ${ }^{-1} .^{17}$ It processes wastewater from a $130 \mathrm{~km}$ long regional network of sewer interceptors and collectors equipped with 19 pumping stations. This station serves Beauport, Vanier, part of Charlesbourg and Quebec City proper. The station eastern is equipped with 4 mechanical rake-cleaned bar screens, 5 aerated grit chamber, 7 laminar clarifiers, 30 biofilters and 5 disinfecting channels with 8480 ultraviolet lamps. The CUQ treatment plant accomplishes primary and physical-chemical treatment of sewage before discharging the treated water into the SaintLawrence River. In phase one, primary and secondary sludge produced during primary and secondary settling of wastewater is forwarded to station East's four sludge thickeners. The proportion of solid matter in the sludge rises from $1 \%$ to $5 \%$. In phase two, the sludge is transformed into dry matter at the treatment plant located at the CUQ incinerator, prior to it is burnt with urban garbage. The sludge is dewatered by a band filter system that produces sludge with a $25 \%(\mathrm{w} / \mathrm{w})$ level of solid content. Floating matter consisting of oil, grease and scum is skimmed from the surface of grit chamber by using a process that introduces air into the water contained in the tanks. An anionic acrylamide polymer is injected at the exit of the grit chamber to agglomerate the destabilized particles for flocculation, which rapidly sediment in the clarifiers. Figure 1 represents a schematic of the treatment process and the different sampling locations.

\section{Sample collection and analysis}

Grab sampling was done over a period of 3 months covering summer and winter months. In total 36 samples ( 3 samples $\times 4$ weeks $\times 3$

Table 2. General wastewater quality data of influent, effluent, grit, primary, secondary and mixed thickened sludge of Quebec Urban Community (CUQ) wastewater treatment plant.

\begin{tabular}{|c|c|c|c|c|c|c|}
\hline Parameters & Influent & $\begin{array}{c}\text { Grit } \\
\text { influent }\end{array}$ & $\begin{array}{l}\text { Primary } \\
\text { sludge }\end{array}$ & $\begin{array}{l}\text { Secondary } \\
\text { sludge }\end{array}$ & $\begin{array}{l}\text { Mixed } \\
\text { sludge }\end{array}$ & Effluent \\
\hline $\mathrm{pH}$ & $7.10 \pm 0.2$ & $6.98 \pm 0.6$ & $5.88 \pm 0.1$ & $6.19 \pm 0.2$ & $6.29 \pm 0.1$ & $7.27 \pm 0.4$ \\
\hline $\mathrm{TS}\left(\mathrm{g} \mathrm{L}^{-1}\right)$ & $2.02 \pm 30$ & $1.2 \pm 0.2$ & $24.14 \pm 1.7$ & $17.46 \pm 2.3$ & $21.67 \pm 4.0$ & $1 \pm 7$ \\
\hline $\mathrm{SS}\left(\mathrm{g} \mathrm{L}^{-1}\right)$ & $0.94 \pm 12$ & $0.53 \pm 0.5$ & $20.16 \pm 1.8$ & $15.19 \pm 1.6$ & $18.94 \pm 2.9$ & $0.3 \pm 5$ \\
\hline $\operatorname{VS}\left(g^{-1}\right)$ & $0.11 \pm 9$ & $0.39 \pm 1.7$ & $16.67 \pm 2.0$ & $12.83 \pm 3.2$ & $10.53 \pm 3.6$ & $0.07 \pm 3$ \\
\hline $\operatorname{VSS}\left(\mathrm{g} \mathrm{L}^{-1}\right)$ & $0.09 \pm 12$ & $0.19 \pm 1.0$ & $18.07 \pm 3.1$ & $7.73 \pm 1.4$ & $6.23 \pm 1.8$ & $0.01 \pm 12$ \\
\hline $\operatorname{TCOD}\left(\mathrm{g} \mathrm{L}^{-1} 1\right)$ & $0.89 \pm 40$ & $7.49 \pm 10$ & $11.6 \pm 30$ & $9.11 \pm 14$ & $8.87 \pm 23$ & $0.56 \pm 26$ \\
\hline $\operatorname{SCOD}\left(\mathrm{g} \mathrm{L}^{-1}\right)$ & $0.20 \pm 18$ & $0.8 \pm 12$ & $0.97 \pm 19$ & $0.88 \pm 9$ & $0.80 \pm 38$ & $0.13 \pm 50$ \\
\hline Ammoniacal nitrogen $\left(\mathrm{g} \mathrm{L}^{-1}\right)$ & $0.007 \pm 2.5$ & $0.005 \pm 9$ & $0.11 \pm 4$ & $0.17 \pm 11$ & $0.1 \pm 18$ & $0.003 \pm 1.3$ \\
\hline Phosphorus ( $\mathrm{g} \mathrm{L}^{-1}$ ) & $0.003 \pm 0.8$ & $0.10 \pm 3$ & $0.023 \pm 12$ & $0.311 \pm 7$ & $0.663 \pm 15$ & $0.001 \pm 0.5$ \\
\hline TOC $\left(\mathrm{g} \mathrm{L}^{-1}\right)$ & --- & $26 \pm 8$ & $783 \pm 18$ & $282 \pm 10$ & $368 \pm 14$ & --- \\
\hline $\operatorname{SOC}\left(g^{-1}\right)$ & $0.16 \pm 3$ & $0.08 \pm 1.0$ & $1.41 \pm 2.3$ & $0.21 \pm 1.8$ & $0.72 \pm 2.0$ & $0.12 \pm 0.6$ \\
\hline Alkalinity ( $\mathrm{g} \mathrm{L}^{-1}$ ) & $0.21 \pm 12$ & $0.36 \pm 10$ & $0.72 \pm 23$ & $0.67 \pm 14$ & $0.55 \pm 8$ & $0.16 \pm 10$ \\
\hline
\end{tabular}

\pm refers to standard error, no. of replicates $=5$ months) were collected from each sampling point (same water body was sampled along the treatment plant processes and samples were taken from each sampling point on the same day) and analysis was carried out in triplicates. Samples were collected in pre-cleaned glass amber bottles with aluminum foil-lined caps and stored under dark conditions at $4 \pm 1^{\circ} \mathrm{C}$. The samples were subject to different analysis including BPA within two to three days to avoid degradation or transformation of native samples.

General wastewater quality data describing the grit, primary, secondary, mixed thickened, dewatered sludge, influent and effluent during the sampling period are presented in Table 2 . Mixed thickened sludge comprised $60 \%$ primary sludge and $40 \%$ secondary sludge. Analysis of $\mathrm{pH}$, total solids (TS), suspended solids (SS), volatile solids (VS), volatile suspended solids (VSS), total and soluble chemical oxygen demand (TCOD and SCOD), ammonia-nitrogen, phosphate, total and soluble organic carbon (TOC and SOC) and alkalinity were carried out as per the Standard Methods. ${ }^{18}$

\section{Sample preparation for BPA analysis}

\section{General}

The overall scheme of the analytical procedure used for the determination of BPA in wastewater (influent, grit influent, effluent and liquid fraction of sludge [grit liquid, primary sludge liquid, secondary sludge liquid and mixed thickened sludge liquid)], sludge (primary sludge, secondary sludge, mixed thickened sludge and dewatered sludge) and solid fraction of sludge (grit residue, primary sludge solid, secondary sludge solid and mixed thickened sludge solid) is shown in 
Figure 2. The liquid fraction of sludge was separated from the solid fraction by centrifugation at $7650 \mathrm{x} \mathrm{g}$ for $15 \mathrm{~min}$ followed by filtration of liquid fraction by acetone-washed 2 $\mu \mathrm{m}$ glass-fiber (Fisherbrand G6 filter circles, Fischer Scientific, Ontario, Canada) in order to remove all colloids and small particles from liquid fraction.

\section{Solid samples (including sludge)}

Sludge and solid fraction of sludge were frozen using liquid nitrogen prior to lyophilization by the freeze-dry system (Dura Freeze Dryer, Kinetics). About 0.5 grams of lyophilized and homogenized sample was transferred to a glass tube and $20 \mathrm{~mL}$ of dichloromethane-methanol $(7: 3, \mathrm{v} / \mathrm{v})$ was added to the tube. The extraction was carried out by microwave assisted extraction method (MARS microwave extractor, CEM Corporation, North Carolina, USA). This system allowed up to 14 extraction vessels to be irradiated simultaneously. Microwave power was $1200 \mathrm{~W}(100 \%)$ and the extraction was performed in a temperature-controlled mode. The extraction temperature was $110 \pm 1^{\circ} \mathrm{C}$ and programmed as follows: ramp to $110 \pm 1^{\circ} \mathrm{C}$ for $10 \mathrm{~min}$, holding at $110 \pm 1^{\circ} \mathrm{C}$ for $10 \mathrm{~min}$. The extract was separated by centrifugation at $7650 \mathrm{x} \mathrm{g}$ for $15 \mathrm{~min}$ and the procedure was repeated three times. The extracts were combined, concentrated to an approximate volume of $1 \mathrm{~mL}$ with gentle stream of nitrogen and redissolved in $100 \mathrm{~mL}$ of HPLC grade water.

\section{Wastewater sample preparation}

Wastewater samples constituting dissolved and particulate matter (250 $\mathrm{mL}$ each) were filtered through an acetone-washed $2 \mu \mathrm{m}$ glass-fiber (Fisherbrand G6 filter circles, Fischer Scientific, Ontario, Canada). About $100 \mathrm{~mL}$ of filtrate was taken and acidified with $1 \mathrm{M}$ acetic acid buffer ( $\mathrm{pH}$ 5.0). ${ }^{19}$ The extraction of WW sample was performed in the similar manner as the clean-up method of sludge, described below.

\section{Clean-up}

Solid phase extraction (SPE) method was used for clean-up and pre-concentration of extract. OASIS HLB 5cc $200 \mathrm{mg}$ LP glass cartridges were fitted in the vacuum manifold (Welch, USA) which was connected to a vacuum pump (Welch Rietschle Thomas, USA) to dispense samples through the cartridges. Cartridges were pre-conditioned by passing 7 $\mathrm{mL}$ of methanol and $3 \mathrm{~mL}$ of HPLC water at a flow rate of $1 \mathrm{~mL} \mathrm{~min}^{-1}$. Sludge extract, solid fraction of sludge extract and WW (100 mL each) were passed at a flow rate of $5 \mathrm{~mL}$ $\mathrm{min}^{-1}$. After pre-concentration, the sorbents were dried by using a vacuum system set at (15) psi. The elution was performed by adding
$2 \times 4 \mathrm{~mL}$ of methanol/dichloromethane (3:1, $\mathrm{v} / \mathrm{v})$ mixture to the cartridge at a flow rate of $1 \mathrm{~mL} \mathrm{~min}{ }^{-1}$ and giving it a wait time of $10 \mathrm{~min}$ in order to give enough duration of contact between the solvent and the adsorbed compounds. The extracts were later evaporated to dryness with a gentle stream of nitrogen and reconstituted with methanol to a final volume of $1 \mathrm{~mL}$ prior to Liquid Chromatography-Mass Spectrometry/Mass Spectrometry (LCMS/MS) analysis.

\section{LC-MS/MS analysis}

LC-MS/MS analyses were performed on a TSQ Quantum Access (Thermo Scientific, Mississauga, Ontario) with a Finnigan sur- veyor LC pump equipped with a 120 -vial capacity sample management system. The analytes were separated on a $3 \mu \mathrm{m}, 100 \times 2.1$ mm Hypersil Gold C18 reverse phase column (Thermo Scientific, Peterborough). The sample injection volume was set at $10 \mu \mathrm{L}$.

A binary mobile phase gradient with water [A] and methanol [B] was used for analyte separation at a flow rate of $200 \mu \mathrm{L} \mathrm{min}{ }^{-1}$. The gradient was performed as isocratic $5 \% \mathrm{~A}$ and $95 \%$ B for 6 min.

\section{Quantification and validation of the method}

Quantitative LC-MS/MS analysis was carried out in negative ionization (NI) condition

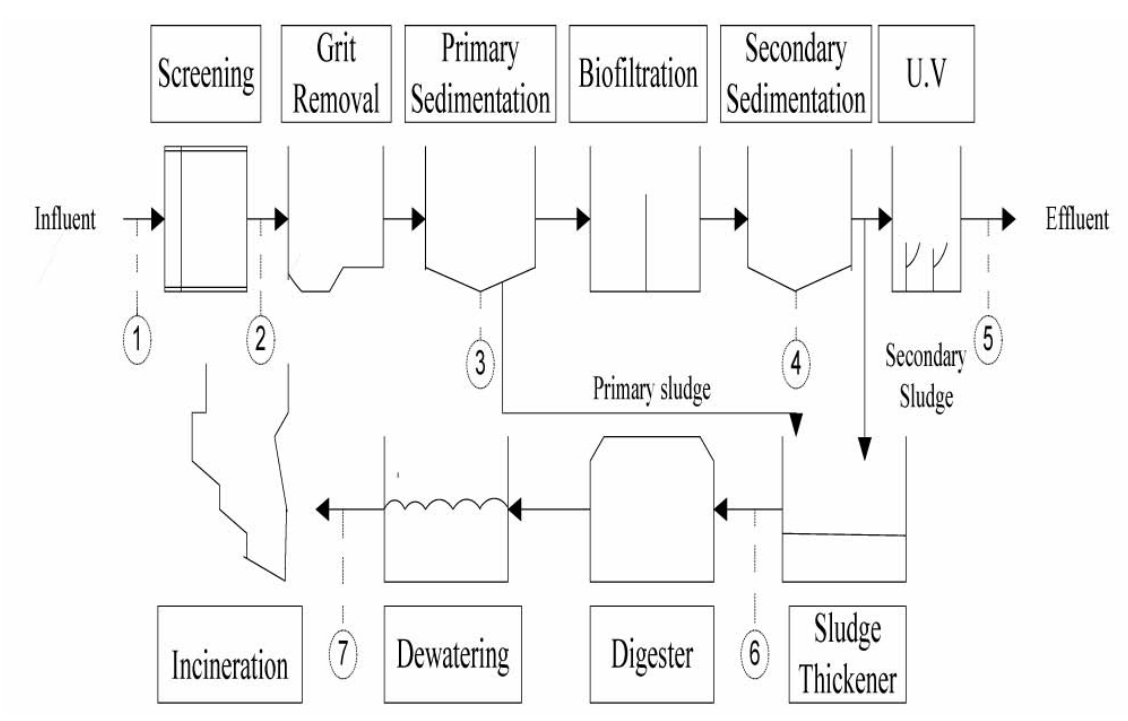

Figure 1. Schematic of the treatment steps of WWTP located in Quebec (Quebec), Canada with different sampling points (1: Influent; 2: Grit influent; 3: Primary sludge;4: Secondary sludge; 5: Effluent; 6: Mixed thickened sludge;7: Dewatered sludge).

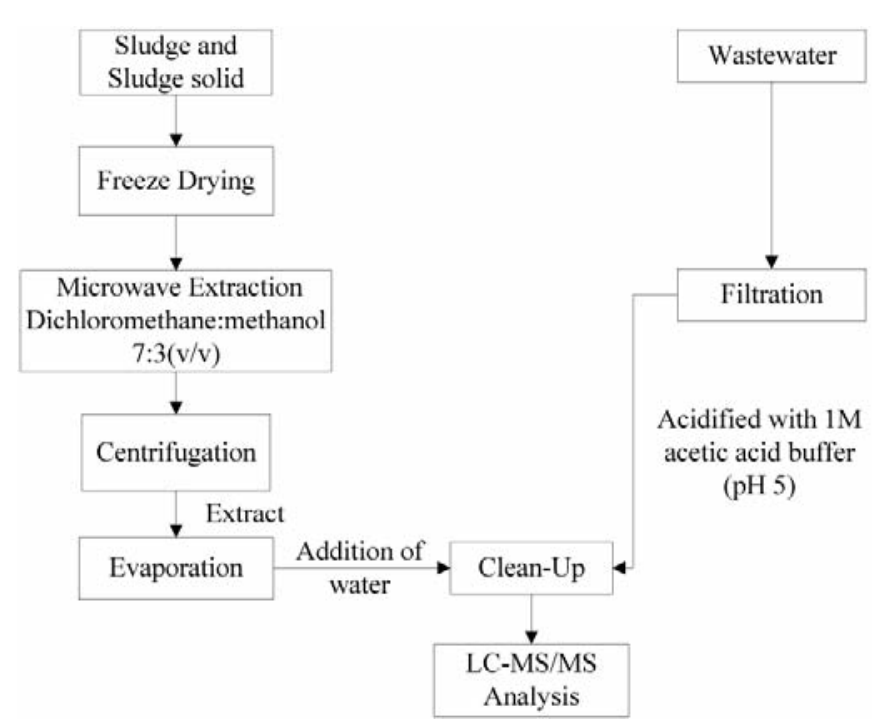

Figure 2. Schematic diagram of analytical procedure used for analysis of bisphenol A in wastewater and wastewater sludge. 
and in selected reactions monitoring (SRM) mode. The optimized operating conditions of LC-MS/MS are presented in Table 3.

Quantification of BPA was performed by the internal standard method based on peak areas and relative retention time, using BPA d16 as internal standard. Four to six-point calibration curves were constructed from the analysis in the SRM mode of WW and WWS samples spiked with the standard mixture of BPA at concentrations ranging between 0.04 to $20 \mu \mathrm{g} \mathrm{\textrm {L } ^ { - 1 }}$. Calibration curve was obtained using linear regression analysis and the established concentration range gave good correlation coefficients $\left(\mathrm{r}^{2}>0.999\right)$.

For estimation of the accuracy and the repeatability of the method, BPA at a concentration of $1.0 \mu \mathrm{g} \mathrm{\textrm {L } ^ { - 1 }}$ for influent, grit influent and $0.2 \mu \mathrm{g} \mathrm{L}^{-1}$ for effluent, $0.2 \mu \mathrm{g} \mathrm{g}^{-1}$ and $0.4 \mu \mathrm{g}$ $\mathrm{g}^{-1}$ for sludge and solid fraction of sludge was spiked. The accuracy of the method was calculated from the areas obtained in the analysis of the spiked samples as a percentage of those obtained in the analysis of a standard solution with an equivalent concentration. The withinday method repeatability was expressed as the relative standard deviation of the ratio of BPA peak area to BPA-d16 area, obtained in the same approach. Limit of detection (LODs) were defined as the concentration of a compound giving a signal-to-noise ratio of 3 .

Recoveries were evaluated in WW, WWS and solid fraction of sludge by analyzing five replicates and then applying the following equation:

$$
\text { recovery }(\%)=\left(C_{m}-C_{0}\right) / C_{s} \quad 1
$$

where, $\mathrm{C}_{\mathrm{m}}=$ measured concentration of the BPA observed in the spiked matrix, $\mathrm{C}_{0}=$ initial concentration of BPA observed in matrix and $\mathrm{C}_{\mathrm{s}}=$ concentration of BPA spiked in the matrix.

In order to investigate the influence of the sludge sample matrix on quantitation of BPA

Table 3. LC-MS/MS conditions used for bisphenol $A$ analysis.

\begin{tabular}{ll} 
Interface-ionization mode & ESI-NI \\
MS acquire time (min) & 6 \\
\hline Scan width (m/z) & 0.01 \\
Scan time (s) & 0.10 \\
\hline Collision energy (V) & 28 \\
Collision gas pressure (mTorr) & 1.7 \\
\hline Spray voltage $(\mathrm{V})$ & 3000 \\
Tube lens & -79 \\
\hline Capillary temperature $\left({ }^{\circ} \mathrm{C}\right)$ & 270 \\
Sheath gas & 15 arbitrary units \\
\hline Auxiliary gas & 5 arbitrary units \\
Sweep gas & 2 arbitrary units \\
\hline SRM setting & $227 \rightarrow 133$ (MRM) \\
\hline
\end{tabular}

by LC-MS/MS, apparent losses in recovery were carried out by preparing sample extracts, originated from sludges and solid fraction of sludge. The sample extracts were divided into two equal aliquots (subsample $\mathrm{A}$ and $\mathrm{B}$ ). Subsample A was spiked with $1.0 \mu \mathrm{g} \mathrm{L}^{-1}$ of BPA and subsample $B$ was used to determine the background (nonspiked) concentrations of BPA. By comparing the responses for BPA in the two subsamples to the responses for the BPA in an external standard (5 $\left.\mu \mathrm{g} \mathrm{L}^{-1}\right)$ using LC-MS/MS, the ion suppression was determined, by using Equation:

$$
\text { Ion suppression }(\%)=\left[1-\left(A_{c}-B_{c}\right)\right] / S_{c} \times 100
$$

where, $A_{c}, B_{c}$, and $S_{c}$ represents peak areas of BPA in subsample A, subsample B, and the analytical standard (S), respectively. In order to confirm whether a higher matrix burden is affecting the extraction on SPE material due to competing matrix components, sludge and solid fraction of sludge samples were spiked with BPA prior to SPE and LC-MS/MS analysis. The experiment was carried out in triplicates.

\section{Rheology study}

\section{Viscosity}

Viscosity of wastewater, different sludges and sludge solids were measured by using a rotational viscometer Brookefield DVII PRO+ (Brookfield Engineering Laboratories, Inc., Stoughton, MA, USA) equipped with Rheocalc32 software. Two different spindles, namely, SC-34 (small sample adaptor), and ultralow centipoise adapter were used with a sample cup volume of $18 \mathrm{~mL} / 50 \mathrm{~mL}$ (spindle dependent). The gaps between spindle and respective sample chamber were 1.235 and $4.830 \mathrm{~mm}$, respectively, for ultralow (viscosity range, $1.0-30 \mathrm{mPa} \mathrm{s}$ ), and small sample (viscosity range, $\geq 30 \mathrm{mPa} s$ ) adapter spindle to accommodate sludge flocs. The calibration and viscosity testing procedure for each spindle was carried out as per the instrument manual. The viscosity data acquisition and analysis was carried out using Rheocalc V2.6 software, (B.E.A.V.I.S. - Brookfield Engineering Advanced Viscometer Instruction Set). All measurements were done at $25 \pm 1^{\circ} \mathrm{C}$ and viscosity was referred to as apparent viscosity.

\section{Particle size analysis}

Particle size analysis was carried out by using Fritsch Laser particle sizer analysette 22 , which is based on LASER diffraction principles. The stirrer and recirculation pump speed were also kept moderate at 250 and 500 rpm, respectively to minimize the damage of sludge particles. For analysis, each sample was diluted approximately 400 -fold in tap water and analyzed in triplicate. This method is based on the principles of Fraunhoffer dif- fraction and Mie scattering. The results were then averaged to produce the particle size distribution, and the readings were recorded as particle volume percent in 51 discrete particle ranges between 0.1 to $1000 \mu \mathrm{m}$. Floc disruption at D43 (volume mean diameter) analogous to the particle size expressed as diameter $43 \%$ size distribution cutoff points was chosen as average particle size as it showed the volume mean diameter. As the sample used is in the liquid form, calculation of distribution based on volume mean as the number mean accurately reflects where the mass or volume of system lies.

\section{Statistical analysis}

All data presented in Table 2, 4, 5 and Figure 3 are representative of at least three independent experiments with all samples measured in triplicates within each experiment. Repetition of statistical results was carried out using Statistical 6.0 software for Windows by employing the Student's t-test.

\section{Results and Discussion}

\section{Recoveries and detection limit}

BPA was extracted in complex aqueous matrices, by using three types of elution with solvents of different polarity or their combination, such as methanol/dichloromethane (9:1, $\mathrm{v} / \mathrm{v})^{20}$ dichloromethane/methanol $(7: 3, \mathrm{v} / \mathrm{v})^{19}$ and dichloromethane/hexane $(4: 1, \mathrm{v} / \mathrm{v})^{21}$ were tested in the SPE clean-up method. The experiments were conducted with five numbers of replications. The results showed higher recovery of BPA with a solvent mixture of methanol/dichloromethane $(9: 1, \mathrm{v} / \mathrm{v})$, during the clean-up method used in this experiment. The recovery of BPA was determined by spiking $1.0 \mu \mathrm{g} \mathrm{L} \mathrm{L}^{-1}$ for influent, grit influent and 0.2 $\mu \mathrm{g} \mathrm{\textrm {L } ^ { - 1 }}$ for effluent and liquid fraction of sludge. In the case of sludge and solid fraction of sludge, $0.2 \mu \mathrm{g} \mathrm{g} \mathrm{g}^{-1}$ and $0.4 \mu \mathrm{g} \mathrm{g}^{-1}$ of BPA was spiked, respectively. Results obtained are shown in Table 4. Recoveries ranged between 90 and 110\% for WW samples and between 85 and $97 \%$ for sludge and solid fraction of sludge, respectively, which demonstrated the validity of the proposed method to analyze WW and WWS samples. It was observed that the lower recovery in sludge and sludge solid samples as compared to wastewater samples was due to the losses by matrix and ion suppression within the SPE method and interface of mass spectrometer respectively. The observed losses due to ion suppression varied between $5-10 \%$.

Repeatability of the method was considered satisfactory, with relative standard deviations varying from $5-12 \%$.The instrumental detection limits (IDL) were performed by consecutively injecting 10 times $2.5 \mathrm{pg}$ of BPA on the 
column. Limit of detection (LOD) was calculated from IDL,22 by considering the amount of sample extracted, the volume of extract analyzed and the recovery rate obtained from a parallel assay of spiked sample. The method's LOD for BPA was $4 \mathrm{ng} \mathrm{\textrm {L } ^ { - 1 }}$ for wastewater sample and $160 \mathrm{ng} \mathrm{kg}^{-1}$ for sludge and solid fraction of sludge sample.

\section{Occurrence of bisphenol A}

As shown in Table 4, BPA was detected in all the process streams of the wastewater treatment plant. It was detected at the highest concentration in the influent where a concentration of $1.68 \mu \mathrm{g} \mathrm{\textrm {L } ^ { - 1 }}$ was observed. A study by
Jackson and Sutton ${ }^{23}$ on source of endocrine disrupting compounds showed a higher concentration of BPA in the influent of the Oakland wastewater treatment plant. The higher concentration of BPA in influent suggests that the sources of BPA in urban wastewater are very significant. Under the sampling conditions of this study, since no precipitation was recorded in the region served by the municipal sewer system in the days preceding the sampling, the flows mainly consisted of domestic, commercial and industrial discharges. Based on moderate water solubility and low vapor pressure, wastewater and washing residue generated during production and processing of application materials, such as polycarbonates and epoxy resins were the most likely industrial sources of release of BPA.

Recycling paper products, such as toilet paper (contributing significantly to wastewater) was considered as a major source of BPA in wastewater ${ }^{24}$ that originates principally from residential region compared to industrial and commercial discharges. The concentration of BPA in grit influent was less as compared to influent. This is mainly due to the presence of preliminary steps in WWTP which includes screening, oil removal and removal of all particles of sand and floating matter where BPA can be adsorbed.

Table 4. Concentration and recovery of bisphenol A in wastewater, sludge and solid fraction of sludge of Quebec Urban Community (CUQ) wastewater treatment plant.

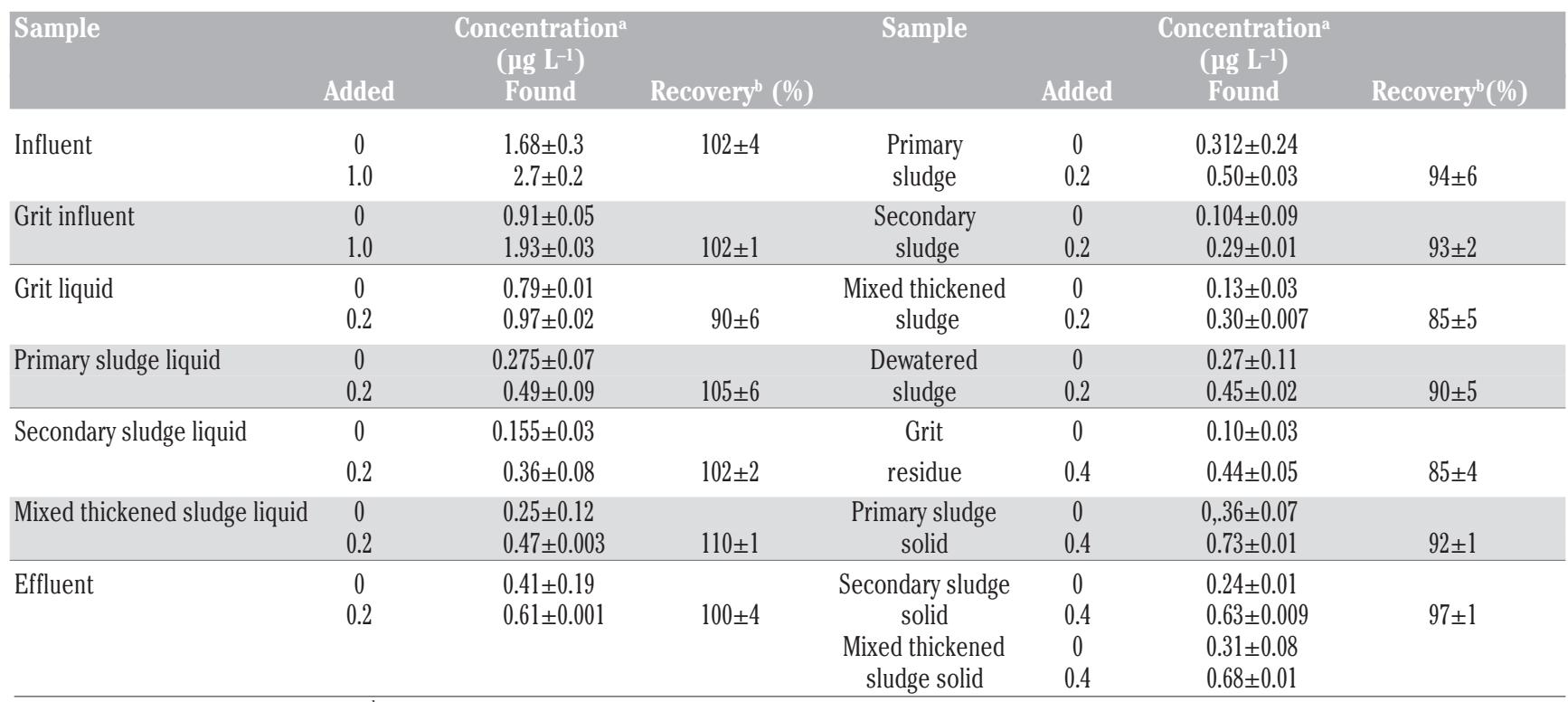

\pm refers to standard error, ${ }^{\mathrm{a}}$ no. of replicates $=3$, ${ }^{\mathrm{b}}$ no. of replicates $=5$

Table 5. Rheological parameters of different samples to estimate adsorption behavior of bisphenol A.

\begin{tabular}{|c|c|c|c|c|c|}
\hline \multirow[t]{2}{*}{ Sample } & \multirow[t]{2}{*}{ Viscosity (mPa.s) } & \multicolumn{4}{|c|}{ Particle size $(\mu \mathrm{m})$} \\
\hline & & $10 \% \leq$ & $50 \% \leq$ & $100 \% \leq$ & $\mathrm{D}_{48}$ \\
\hline Influent & $7.3 \pm 4$ & 10.4 & 30.8 & 490.7 & 56.8 \\
\hline Grit influent & $6 \pm 3.6$ & 6.2 & 24.2 & --- & 35 \\
\hline Grit decanted & $5.2 \pm 3.2$ & --- & --- & --- & --- \\
\hline Primary sludge decanted & $5.42 \pm 3.8$ & --- & --- & --- & --- \\
\hline Secondary sludge decanted & $5.9 \pm 1.4$ & --- & --- & --- & --- \\
\hline Mixed sludge decanted & $4.9 \pm 2.7$ & --- & --- & --- & --- \\
\hline Effluent & $5.26 \pm 2.7$ & --- & --- & --- & --- \\
\hline Primary sludge & $197 \pm 7.3$ & 10 & 76 & 490 & 158 \\
\hline Secondary sludge & $13 \pm 4.5$ & 8.5 & 38 & 410 & 52.5 \\
\hline Mixed sludge & $9 \pm 6.8$ & 6.8 & 27.9 & 262.4 & 40.2 \\
\hline Dewatered sludge & --- & 50 & 256 & 132 & 249 \\
\hline Grit residue & $125.8 \pm 6$ & --- & -- & --- & --- \\
\hline Primary sludge solid & $178 \pm 7.4$ & --- & --- & --- & --- \\
\hline Secondary sludge solid & $93.9 \pm 5.1$ & --- & -- & --- & --- \\
\hline Mixed sludge solid & $173 \pm 4.6$ & --- & -- & --- & --- \\
\hline
\end{tabular}


The concentration of BPA observed in wastewater is in agreement with Lee et al., ${ }^{12}$ who reported BPA at $\mu \mathrm{g} \mathrm{L}^{-1}$ levels, in the wastewater samples of many commercial laundries as well as final effluents of WWTP in Canada. The concentration underwent a significant reduction in effluent $\left(0.41 \mu \mathrm{g} \mathrm{L}^{-1}\right)$ during the course of treatment stages, indicating that BPA is efficiently removed from wastewater. The low vapor pressure of BPA $\left(8.7 \times 10^{-10}\right.$ to $3.96 \times 10^{-7} \mathrm{mmHg}$ ) indicated its poor volatilization during the treatment process, thus confirming the fact that the different stages of treatment within the WWTP were capable of removing the pollutant from the contaminated media. The report issued by Environment Canada stated that the average reduction of BPA in Canadian sewage treatment plants, based on a study of 36 facilities in 2000 is $68 \%$, with reduction of over $50 \%$ requiring secondary waste treatment processes.

Among the four liquid fractions of sludge (grit liquid, primary sludge liquid, secondary sludge liquid and mixed thickened sludge liquid), BPA was detected at highest concentration in grit liquid and lowest in secondary sludge liquid. The higher concentration of BPA in grit liquid was due to high concentration of BPA observed in grit influent. Among the three type of sludge liquid, the higher concentration of BPA was observed in primary sludge liquid. However, the concentration detected in the liquid fraction of sludge was found to very low as most of BPA was removed with the solids. The concentration of BPA in primary sludge liquid was higher (Table 4) due to the higher solid concentration (Table 2) as compared to the secondary and mixed sludge liquid. As the mixed sludge contained both primary and secondary sludge, the concentration of BPA detected was found to be more as compared to secondary sludge liquid. A relatively high octanol-water partition coefficient $\left(\log K_{\text {ow }}=\right.$ 2.3-3.82) of $\mathrm{BPA}^{25}$ suggests that BPA is strongly associated with oily solids and droplets suspended in the wastewater. It might be the reason for detection of higher concentration of the compound in primary sludge liquid. During primary treatment, there is addition of coagulant, and hence removal of compound occurs, so that the detected concentration in secondary sludge liquid is lower.

BPA was detected in all types of sludge and sludge solids. Among the four types of sludge (primary sludge, secondary sludge, mixed thickened sludge and dewatered sludge), the highest concentration of BPA was found in primary sludge and lowest in secondary sludge. In an earlier study, ${ }^{26}$ the concentration of BPA in raw sludge was reported as 0.10 and $0.13 \mu \mathrm{g} \mathrm{g}^{-1}$ in Quebec City. The higher concentration of BPA detected in primary sludge was due to higher solids concentration as the compound is adsorbed on solids due to high $\log \mathrm{K}_{\mathrm{ow}}$ value and hydrophobic nature. The concentration of BPA in secondary sludge was reported less as compared to primary sludge as physical-chemical treatment resulted in removal of compound via adsorption onto solids. For example, it has been reported that adsorption of organic compounds onto solids is the most important mechanism of removal during primary treatment for compounds with higher $\log \mathrm{K}_{\mathrm{ow}}$ values. ${ }^{6}$ The concentration of BPA observed in mixed thickened sludge was found to be higher as compared to secondary sludge as the mixed thickened sludge contained both primary sludge (higher \%) and secondary sludge. The concentration of BPA observed in dewatered sludge was $0.27 \mu \mathrm{g} \mathrm{g} \mathrm{g}^{-1}$. The concentration of BPA observed in primary sludge and dewatered sludge, showed that the different stages of treatment within the treatment plant were not equally capable of removing the pollutant from sludge.

Among the solids fraction of sludge (grit residue, primary sludge solid, secondary sludge solid and mixed sludge solid), the highest BPA concentration $\left(0.36 \mu \mathrm{g} \mathrm{g}^{-1}\right)$ was detected in primary sludge solids. The concentration of BPA observed in mixed thickened sludge solid was higher as compared to secondary sludge solid as mixed sludge constitutes more percentage of primary sludge.

\section{Estimation of daily mass flow}

The estimation of daily mass flows of BPA is presented in Figure 3. The results presented can be considered as preliminary estimates of development of preneoplastic and neoplastic of quantity BPA distributed in various streams of WWTP.

Approximately $580 \mathrm{~g} \mathrm{~d}^{-1}$ of BPA was received by WWTP. Following treatment, approximately $24 \%$ of BPA was discharged in the effluent into receiving surface water (Saint-Lawrence River). It can be seen that appreciable amounts (76\%) of BPA was removed by physico-chemical treatment process. It is unequivocal that the WWTP in efficient for removal of BPA from aqueous phase. However, the small concentration of pollutant discharged to the river cannot be neglected as the aquatic compartment has been identified as the main compartment in which BPA may be found. ${ }^{27}$

$\mathrm{BPA}$ is present in the effluent in environmentally important concentrations that may cause physiological effects in aquatic life. Meanwhile, BPA is known to have half-life of 3$6 \mathrm{~d}^{28}$ which may cause its rapid removal from river, nevertheless a constant concentration is being added each day. Finally, there is a possibility of ingestion by aquatic organisms, such as invertebrates resulting in potential aquatic toxicity.

Study by Murray et al..$^{29}$ showed that in situ fetal exposure to 2.5, 25, 250 and $1000 \mu \mathrm{g}$ $\mathrm{BPA} / \mathrm{kg}$ body weight/day induced the development of ductal hyperplasias and carcinoma at postnatal day 50 and 95 in rats. These highly proliferative lesions have an increased number of estrogen receptor- $\alpha$ positive cell. Thus, fetal BPA exposure is sufficient to induce the mass balance which is a reasonable estimation cevelopment of preneoplastic and neoplastic

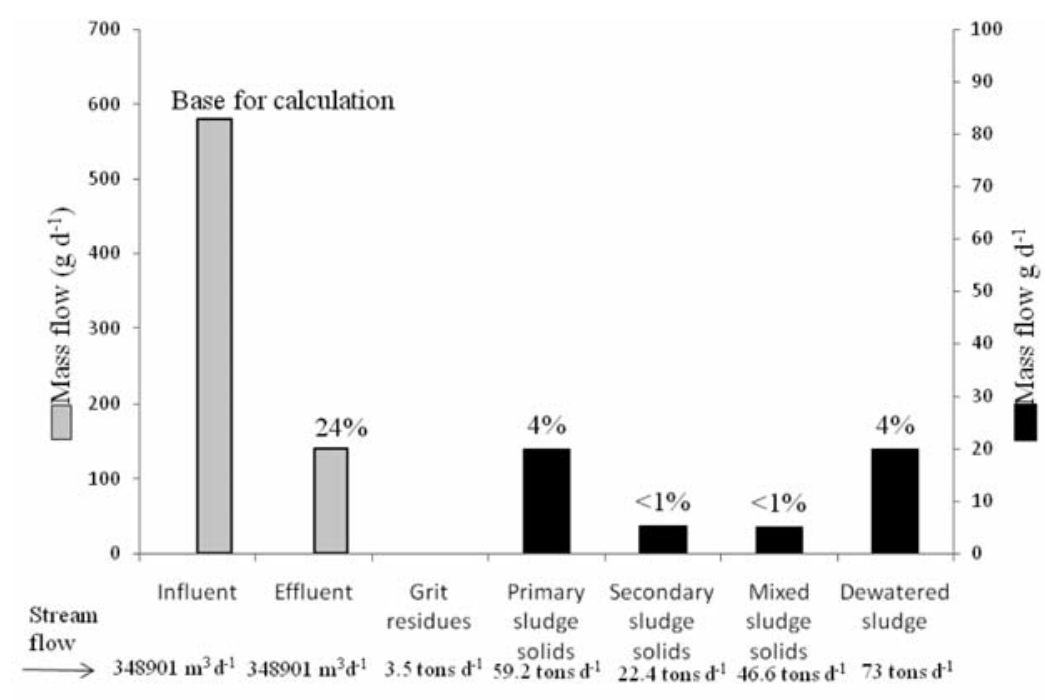

Figure 3. Estimation of daily mass flows of bisphenol A (BPA) in wastewater and sludge of the CUQ treatment plant and quantities of BPA in these streams expressed relative to those observed in the influent (in \%). The mass balance of BPA along the different units of WWTP was carried out by using the equation: $m=Q \times S$ where $m$ is the mass flow $(g$ $\mathrm{d}-1), Q$ is stream flow ( $\mathrm{m} 3 \mathrm{~d}-1$ or tons $\mathrm{d}-1)$ and $S$ is the concentration of BPA ( $\mu \mathrm{g} \mathrm{L-1}$ or $\mu \mathrm{g}$-1). Value of $Q$ was calculated by averaging the stream flow in each unit during the day of sampling up to four months. 
lesions in the mammary gland in the absence of any additional treatment aimed at increasing tumor development.

With respect to the analyzed solid residues, grit residues, secondary and mixed sludge solid did not represent an important output for BPA. In contrast, $4 \%$ of BPA was found in dewatered sludge, which was subsequently incinerated. The dewatered sludge from the CUQ WWTP is incinerated at approximately $900^{\circ} \mathrm{C}$, which mineralizes the organic components. Hence, it is presumed that BPA would be absent from ash residues or else there is a possibility that $\mathrm{Cl}_{2}$ will react with $\mathrm{OH}$ group of $\mathrm{BPA}$ to form dioxins (potential EDCs). In fact, phenols are known to form dioxins due to interaction of chlorine with $-\mathrm{OH}$ groups. ${ }^{30}$

The reduction in sludge volume by incineration produces secondary environmental pollution and is cost intensive. Hence, if incineration was discontinued for beneficial end use of sludge such as land application (agriculture) and land spreading, the presence of BPA might raise question in sludge reuse with further possibility of contamination of groundwater aquifers.

\section{Effects of rheology}

Sorption and desorption are important factors in estimating the transport, transformation, degradation and fate of BPA in the environment. There have been a number of studies focused on the adsorption/partition behavior of BPA. $^{31}$ Meanwhile, sorption and desorption also become key parameters for its transport in WWTPs for both wastewater and sludge. Rheology is a parameter which aids in a better understanding of the flow properties of WW and sludge within WWTPs.

Table 5 represents apparent viscosity of wastewater, sludges and solid fraction of sludge. Highest apparent viscosity was observed in primary sludge $(197 \pm 7.3 \mathrm{mPa} s)$ and the value suddenly decreased in secondary sludge $(13 \pm 4.5 \mathrm{mPa} \mathrm{s})$. The decrease in viscosity was mainly due to decrease in total solids concentration from primary sludge to secondary sludge. At higher solids content, structural units of the suspension is typically suggested to be larger in size and knitted close to each other. As particle concentration increases, a network of particles is formed with the number of interactions increasing rapidly with the volume concentration of particles and thus leading to increase in resistance to flow of sludge materials. ${ }^{32}$ Therefore, as solids content increases, the viscosity increases and vice versa at constant shear rate.

The treatment processes within the WWTP will typically influence the rheological behavior by modifying overall sludge properties, including structure, strength and size of sludge flocs and sludge composition. BPA is hydrophobic which implies that the compound is strongly associated with sludge flocs.

As the size of the flocs decreases from primary sludge to secondary sludge, the apparent viscosity decreases. Thus, overall bioavailability and rates of biodegradation of sorbed BPA increases which may be the reason for decrease in observed concentration of BPA from primary to secondary sludge $\left(0.312 \mu \mathrm{g} \mathrm{g}^{-1}\right.$ to $\left.0.104 \mathrm{\mu g} \mathrm{g}^{-1}\right)$. The effect of different treatment processes within the treatment plant on rheological behavior is mainly attributed to hydromechanical shear forces which can disintegrate sludge aggregates and disrupt cells, thus breaking the microbial slurry where the particles constantly interact with each other that influence on decrease in viscosity.

In order to observe the partitioning of BPA, the apparent viscosity of sludge solids and sludge liquid were measured. The viscosity of sludge solids was higher as compared to sludge liquid in all three types of sludge as expected. The highest viscosity was observed in primary sludge solid (178 mPa.s) where the partitioning of BPA was also observed more in solid $\left(0.36 \mu \mathrm{g} \mathrm{g} \mathrm{g}^{-1}\right)$ as compared to its liquid part $\left(0.275 \mu \mathrm{g} \mathrm{L}^{-1}\right)$.

Table 5 presents the volume particle size distribution (volume mean diameter) of influent, grit influent, primary, secondary, mixed thickened and dewatered sludge. The highest particle size was observed in primary sludge (158 $\mu \mathrm{m})$ and the value decreased in secondary sludge $(52.5 \mu \mathrm{m})$ and mixed thickened sludge $(40.2 \mu \mathrm{m})$. The decrease in particle size in secondary and mixed thickened sludge was mainly due to different treatment process within the treatment plant. The decrease in particle size will thus result in large number of small particles per unit volume of the medium so that BPA was adsorbed on these larger surface flocs. Further, different microorganisms present within the medium will have improved access to BPA and finally favor biodegradation during secondary treatment. As a result, the BPA concentration observed in secondary sludge $\left(0.104 \mu \mathrm{g} \mathrm{g}^{-1}\right)$ and mixed thickened sludge $\left(0.13 \mu \mathrm{g} \mathrm{g}^{-1}\right)$ was less as compared to primary sludge $\left(0.312 \mu \mathrm{g} \mathrm{g}^{-1}\right)$, thus in direct correlation with the results. Results in the laboratory have demonstrated that BPA spiked pre-treated sludge (decrease in particle size) 33 , resulted in enhanced growth of Rhizobium sp. which confirmed the earlier statement.

Hence, this study points to an urgent need for source control of BPA as there is continuous addition of BPA into the environment and despite some removals, the conversion is still questionable. Studies are being carried out in the laboratory in this regard to estimate the byproducts of BPA during various process streams and also during various pre-treatments.

[Journal of Xenobiotics 2011; 1:e3]

\section{Conclusions}

This study demonstrated that BPA was present in influent, effluent, primary, secondary, mixed thickened and dewatered sludge in varying concentration $\left(0.07 \mu \mathrm{g} \mathrm{L}^{-1}\right.$ to $1.68 \mu \mathrm{g} \mathrm{\textrm {L } ^ { - 1 }}$ in

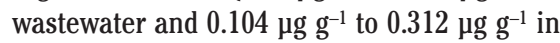
wastewater sludge) within the CUQ WWTP. The pollutant was discharged into SaintLawrence River at levels that may cause physiological effects in wildlife. However, the river water may also have a diluting effect, reducing BPA concentration and consequently the availability of pollutant for absorption by aquatic organisms. The treatment plant was able to accomplish the removal of BPA from the aqueous phase, but significant amount of $0.41 \mu \mathrm{g}$ $\mathrm{L}^{-1}$ still remained in the treated process stream. In the case of wastewater sludge, a significant quantity of BPA $\left(0.29 \mu \mathrm{g} \mathrm{g} \mathrm{g}^{-1}\right)$ was present in dewatered sludge, questioning the reuse and recycle of the sludge.

The different treatment processes within the WWTP caused decrease in apparent viscosity, increase in solubilization, thus leading to more biodegradation of BPA due to enhanced mass and oxygen transfer. The decrease in particle size during different treatment steps resulted in formation of more number of small particles per unit volume of medium helping in higher adsorption of BPA to large surface flocs and improved biodegradation during secondary treatment.

\section{References}

1. Bautista TI, Ferro GMA, Rivera UJ, et al. Bisphenol A removal from water carbon. Effects of carbon characteristics and solution chemistry. Environ Sci Technol 2005;39:6246-50.

2. Mohapatra DP, Brar SK, Tyagi RD, Surampalli RY. Physico-chemical pretreatment and biotransformation of wastewater and wastewater sludge-Fate of bisphenol A. Chemosphere 2010;78:92341.

3. Korner W, Bolz U, Sumuth W, et al. Input/output balance of estrogenic active compounds in a major municipal sewage plant in Germany. Chemosphere 2000;40: 1131-42.

4. Wintgens T, Gallenkemper M, Melin T. Occurrence and removal of endocrine disrupters in landfill leachate treatment plants. Water Sci Technol 2003;48:127-34.

5. Environment Canada. Draft Screening Assessment for The Challenge: Phenol, 4,4'-(1 methylethylidene)bis-(BPA). Chemical Abstracts Service Registry No. 80-05-7, 2008. Available from: 
http://www.ec.gc.ca/ substances/ese/ eng/ challenge/batch2/batch2_80-057.cfm

6. Mohapatra DP, Brar SK, Tyagi RD, Surampalli RY. Degradation of endocrine disrupting bisphenol A during pre-treatment and bio-transformation of wastewater sludge. Chem Eng J 2010;163:27383.

7. Langford KH, Lester JN. Fate and behavior of endocrine disruptors in wastewater treatment processes. In: Brikett JW, Lester JN, eds. Endocrine Disrupters in Wastewater and Sludge Treatment Processes. London, UK: Lewis Publisher \& IWA Publishing; 2003. pp. 103-144.

8. Jing XL, Jiang GB, Huang G. Determination of 4-tertoctylphenol, 4nonylphenol and BPA in surface waters from the Haihe River in Tianjin by gas chromatography-mass spectrometry with selected ion monitoring. Chemosphere 2004;56:1113-19.

9. Mohapatra DP, Brar SK, Tyagi RD, Surampalli RY. Parameter optimization of ferro-sonication pre-treatment process for degradation of BPA and biodegradation from wastewater sludge using response surface model. J Hazard Mater 2011;189: 100-7.

10. Mohapatra DP, Brar SK, Tyagi RD, Surampalli RY. Concomitant degradation of bisphenol A during ultrasonication and Fenton oxidation and production of biofertilizer from wastewater sludge. Ultrason Sonochem 2011;18:1018-27.

11. Canada Gazette. Draft screening assessment and the risk management scope forphenol, 3,3"-(methylethylidene)bis(Bisphenol A), CAS No. 80-05-7. Canada Gazette Notice Part 1, 2008, Vo. 142, No. 16.

12. Lee HB, Peart TE, Gris G, Chan J. Endocrine-disrupting chemicals in industrial wastewater samples in Toronto, Canada. Water Qual Res J Can 2002;37: 459-72.

13. Pothitou P, Voutsa D. Endocrine disrupting compounds in municipal and industrial wastewater treatment plants in Northern
Greece. Chemosphere 2008;73:1716-23.

14. Fuerhacker M. Bisphenol A emission factors from industrial sources and elimination rates in a sewage treatment plants. Water Sci Technol 2003;47:117-22.

15. Kang JH, Aasi D, Katayama Y. Bisphenol A in the aquatic environment and its endocrine-disruptive effects on aquatic organisms. Crit Rev Toxicol 2007;37:60725 .

16. Verma M, Brar SK, Tyagi RD, et al. Wastewater sludge as a potential raw material for antagonistic fungus (Trichoderma sp.): role of pre-treatment and solids concentration. Water Res 2005;39:3587-96.

17. Quebec Urban Community brochure. Wastewater Treatment Plant, Beauport, Quebec city, Quebec, Canada, 2009. Available from: http://services.ville.quebec.qc.ca/station/an.htm

18. APHA, AWWA, WEF. Standard Methods for the Examination of Water and Wastewater, 21st ed. Washington, DC: American Public Health Association; 2005.

19. Mauricio R, Diniz M, Petrovic M, et al. A characterization of selected EDCs in a Portuguese wastewater treatment plant. Environ Monitor Assess 2006;118:75-87.

20. Petrovic M, Barcelo D. Determination of anionic and nonionic surfactants, their degradation product and EDCs in sewage sludge by LC-MS. Anal Chem 2000;72: 4560-7.

21. Gatidou G, Thomaidis NS, Stasinakis AS, Lekkas TD. Simultaneous determination of the endocrine disrupting compounds nonylphenol, nonylphenol ethoxylates, triclosan and bisphenol A in wastewater and sewage sludge by gas chromatographymass spectrometry. J Chromatogr A 2007; 1138:32-41.

22. Petrovic M, Barceló D, Diaz A, Ventura F. Low nanogram per liter determination of halogenated nonylphenols, nonylphenol carboxylates, and their non-halogenated precursors in water and sludge by liquid chromatography electrospray tandem mass spectrometry. J Am Soc Mass
Spectrom 2003;14:516-27.

23. Jackson J, Sutton R. Sources of endocrinedisruptting chemicals in urban wastewater, Oakland, CA. Sci Total Environ 2008;405:153-60.

24. Gehring M. Contributions to waste management and contaminated sites. Series of the Institute of Waste Management and Contaminated Sites the Technical University of Dresden. 2004. pp. 34.

25. Staples CA, Dorn PB, Klecka GM, et al. A review of the environmental fate, effects, and exposures of bisphenol A. Chemosphere 1998;36:2149-73.

26. Lee HB, Peart TE. Organic contaminants in Canadian municipal sewage sludge. Part I. Toxic or endocrine-disrupting phenolic compounds. Water Quality Res J Can 2002;37:681-96.

27. Cousins IT, Staples CA, Klecka GM, Mackay D. A multimedia assessment of the environmental fate of bisphenol A. Human Ecol Risk Assess 2002;8:1107-35.

28. Kang JH, Aasi D, Katayama Y. Bisphenol A in the aquatic environment and its endocrine-disruptive effects on aquatic organisms. Crit Rev Toxicol 2007;37:60725.

29. Murray TJ, Maffini MV, Ucci AA, et al. Induction of mammary gland ductal hyperplasias and carcinoma in situ following fetal bisphenol A exposure. Reprod Toxicol 2007;23:383-90.

30. Lu S, Yan J, Li X, et al. Effects of inorganic chlorine source on dioxin formation using fly ash from a fluidized bed incinerator. J Environ Sci (China) 2007;19:756-61.

31. Zhao J, Li Y, Zhang C, et al. Sorption and degradation of BPA by aerobic activated sludge. J Hazar Mater 2008;155:305-11.

32. Mikkelsen LH. The shear sensitivity of activated sludge. Relations to filterability, rheology and surface chemistry. Coll Surf A Physicochem Eng Aspects 2001;182:1-14.

33. Pham TTH, Brar SK, Tyagi RD, Surampalli RY. Influence of ultrasonication and Fenton oxidation pre-treatment on rheological characteristics of wastewater sludge. Ultrason Sonochem 2010;17:38-45. 